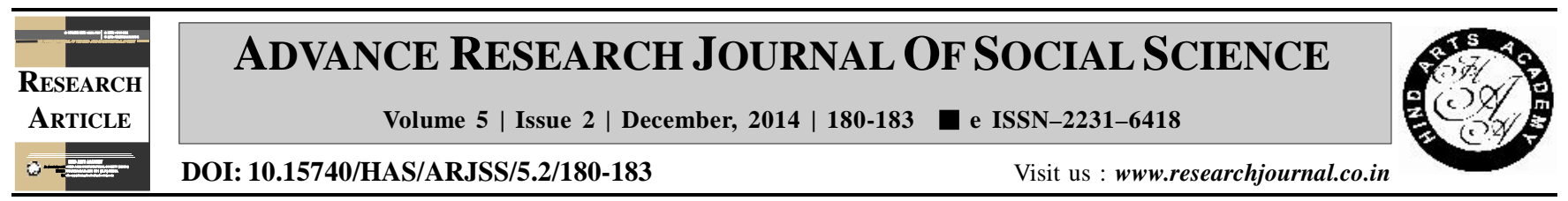

\title{
Mental stress of college students across gender
}

Mamta Kumari* and Sunita Mishra ${ }^{1}$

Department of Human Development and Family Studies, School for Home Science, Babasaheb Bhimrao Ambedkar University, LUCKNOW (U.P.) INDIA

(Email: missmamtu@gmail.com)

\section{ARTICLE INFO :}

Received

Revised

: 01.09 .2014

Accepted

: 08.11 .2014

KEY WORDS :

Mental stress, Higher education, College students, Stressful situation

\section{HOW TO CITE THIS ARTICLE :}

Kumari, Mamta and Mishra, Sunita (2014). Mental stress of college students across gender. Adv. Res.

J. Soc. Sci., 5 (2) : 180-183.

*Author for correspondence

\begin{abstract}
Mental stress is a very familiar condition faced by students when they are unable to bear the risk involved in higher education. College students are exposing to very stressful situation. Some researcher found that stressful situation faced by student when leaving home for the first time and going away for school can be very difficult for some people. The study aimed to assess the level of mental stress among college students. A study was conducted in the Lucknow city of Uttar Pradesh. A total of 120 sample were collected from the selected college using the simple random sampling method. A sample comprised 40 students from each selected colleges including both of the sexes. A mental stress questionnaire used to assess the level of mental stress used by college students. The study findings revealed that majority (80\%) of respondents had moderate level of stress and there are significant difference between gender and mental stress. Boys had more stress than the girls.
\end{abstract}

